\title{
MAGE-A4, NY-ESO-1 and SAGE mRNA expression rates and co-expression relationships in solid tumours
}

Mikiya Ishihara ${ }^{1 *}\left(\mathbb{D}\right.$, Shinichi Kageyama ${ }^{2 *}$, Yoshihiro Miyahara ${ }^{3}$, Takeshi Ishikawa ${ }^{4}$, Shugo Ueda ${ }^{5}$, Norihito Soga ${ }^{6}$, Hiroaki Naota ${ }^{7}$, Katsumi Mukai ${ }^{8}$, Naozumi Harada ${ }^{9}$,Hiroaki Ikeda ${ }^{10}$ and Hiroshi Shiku ${ }^{2,3}$

\begin{abstract}
Background: Cancer testis (CT) antigens are promising targets for cancer immunotherapies such as cancer vaccines and genetically modified adoptive T cell therapy. In this study, we evaluated the expression of three CT antigens, melanoma-associated antigen A4 (MAGE-A4), New York oesophageal squamous cell carcinoma 1 (NY-ESO-1) and sarcoma antigen gene (SAGE).
\end{abstract}

Methods: MAGE-A4, NY-ESO-1 and/or SAGE antigen expression in tumour samples was evaluated by quantitative real-time polymerase chain reaction (qRT-PCR). Informed consent was obtained from individuals prior to study enrolment.

Results: In total, 585 samples in 21 tumour types were evaluated between June 2009 and March 2018. The positive expression rates of these CT antigens were as follows: MAGE-A4, 34.6\% (range, 30.7-38.7); NY-ESO-1, 21.0\% (range, 17.2-25.1); and SAGE, 21.8\% (range, 18.5-25.4). The MAGE-A4 antigen was expressed in 54.9\% of oesophageal cancers, $37.5 \%$ of head and neck cancers, $35.0 \%$ of gastric cancers and $34.2 \%$ of ovarian cancers; the NY-ESO-1 antigen was expressed in $28.6 \%$ of lung cancers, $25.3 \%$ of oesophageal cancers and $22.6 \%$ of ovarian cancers; and the SAGE antigen was expressed in $35.3 \%$ of prostate cancers, $32.9 \%$ of oesophageal cancers and $26.3 \%$ of ovarian cancers. The most common tumour type in this study was oesophageal cancer. MAGE-A4, NY-ESO-1 and SAGE antigen expression were assessed in 214 oesophageal cancer samples, among which 24 (11.2\%) were triple-positive, 58 (27.1\%) were positive for any two, 59 (27.6\%) were positive for any one, and 73 (34.1\%) were triple negative.

Conclusions: Oesophageal cancer exhibited a relatively high rate of CT antigen mRNA expression positivity.

Keywords: MAGE-A4, NY-ESO-1, qRT-PCR, SAGE, Solid tumour

\footnotetext{
*Correspondence: mishihara@clin.medic.mie-u.ac.jp;

kageyama@clin.medic.mie-u.ac.jp

${ }^{1}$ Cancer Center, Mie University Hospital, 2-174 Edobashi, Tsu, Mie 514-8507,

Japan

${ }^{2}$ Department of Immuno-Gene Therapy, Mie University Graduate School of

Medicine, 2-174 Edobashi, Tsu, Mie 514-8507, Japan

Full list of author information is available at the end of the article
}

(c) The Author(s). 2020 Open Access This article is licensed under a Creative Commons Attribution 4.0 International License, which permits use, sharing, adaptation, distribution and reproduction in any medium or format, as long as you give appropriate credit to the original author(s) and the source, provide a link to the Creative Commons licence, and indicate if changes were made. The images or other third party material in this article are included in the article's Creative Commons licence, unless indicated otherwise in a credit line to the material. If material is not included in the article's Creative Commons licence and your intended use is not permitted by statutory regulation or exceeds the permitted use, you will need to obtain permission directly from the copyright holder. To view a copy of this licence, visit http://creativecommons.org/licenses/by/4.0/ The Creative Commons Public Domain Dedication waiver (http://creativecommons.org/publicdomain/zero/1.0/) applies to the data made available in this article, unless otherwise stated in a credit line to the data. 


\section{Background}

Cancer testis (CT) antigens are anticipated to be optimal targets for cancer immunotherapy because their expression is limited to the testis and placenta in normal tissue [1]. Since T. Boon et al. reported that melanomaassociated antigen (MAGE), a CT antigen, was recognized by $\mathrm{T}$ cells [2], many researchers have studied the potential of CT antigens as cancer immunotherapy targets [3]. Not only immune checkpoint inhibitors but also genetically modified $\mathrm{T}$ cell therapies, such as chimeric antigen receptor (CAR) and $\mathrm{T}$ cell receptor (TCR)-engineered $\mathrm{T}$ cell therapies, have been developed in this era of cancer immunotherapy [4-6]. CT antigens are anticipated to be target proteins for genetically modified $\mathrm{T}$ cell therapy.

MAGE-A4 [7, 8], New York oesophageal squamous cell carcinoma 1 (NY-ESO-1) [9-11] and sarcoma antigen gene (SAGE) [12] are CT antigens. Our group studied MAGE-A4- and SAGE-derived T cell epitopes [13] and conducted clinical trials using a cancer vaccine and/ or TCR-engineered T cells targeting MAGE-A4- or NYESO-1-expressing tumours [14-19]. Before patients were enrolled in those clinical trials, CT antigen expression in tumour samples obtained from the patients was assessed as another clinical study, and we report the results here.

\section{Methods}

\section{MAGE-A4, NY-ESO-1 and SAGE expression}

RNA extraction was performed as described previously [20]. In brief, total RNA was extracted from frozen tissue samples, and complementary DNA (cDNA) was then prepared using a QuantiTect Reverse Transcription kit (Qiagen, Hilden, Germany). qRT-PCR was routinely performed. The sequences of the primers and probes used in our study were as follows: MAGE-A4, F: 5'-GCAGTAATCCTGCGCGCTAT3' and R: 5' -CATTGACCCTGACCACATGCT-3'; probe: 5'-FAM-CTCTGGCTGAAACCA-MGB-3'. NY-ESO-1, F: 5'-GGCTGAATGGATGCTGCAGA-3' and R: 5' CTGGAGACAGGAGCTGATGGA-3'; probe: 5'-FAMTGTGTCCGGCAACATACTGACTATCCGA-TAMRA3'. SAGE, F: 5'-TGTCATTCACGATATCCAGGAGG-3' and R: 5'-GGTGGCATACAATGTCCTGTCAT-3'; probe: 5'-FAM-TGTGTCCGGCAACATACTGACTATCCGA-

TAMRA-3'. Gene expression was evaluated as positive when the value exceeded 12.2 copies $/ 10^{4}$ copies of glyceraldehyde3-phosphate dehydrogenase (GAPDH) for MAGE-A4, 5.96 copies $/ 10^{4}$ copies of GAPDH for NY-ESO-1 and 2.81 copies $/ 10^{4}$ copies of GAPDH for SAGE. These cut-off values were determined as the means \pm 2 standard deviations (SDs) of the expression levels in the corresponding normal samples.

\section{Statistical analysis}

Pearson's chi-squared test of independence was used to evaluate associations between 2 variables. $P$-values of less than 0.05 were considered statistically significant. Calculations were performed with SPSS Statistics version 25 (IBM Japan, Ltd., Tokyo, Japan).

\section{Results}

\section{CT antigen mRNA expression in tumours}

Five hundred and 85 samples were collected and evaluated for MAGE-A4, NY-ESO-1 and/or SAGE expression between June 2009 and March 2018. The expression rates of MAGE-A4, NY-ESO-1 and SAGE were 34.6, 21.0 and $21.8 \%$, respectively (Table 1 ).

Twenty-one tumour types were included in this study. The tumour types for which 5 or more samples were evaluated are listed in Tables 2-4. MAGE-A4 expression was evaluable in 575 samples. The MAGE-A4 expression rate was high in oesophageal cancer (54.9\%), head and neck cancer $(37.5 \%)$, gastric cancer $(35.0 \%)$ and ovarian cancer (34.2\%) (Table 2).

NY-ESO-1 was evaluable in 439 samples. The NY-ESO1 expression rate was high in lung cancer (28.6\%), oesophageal cancer (25.3\%) and ovarian cancer (22.6\%) (Table 3). Although the number of evaluable samples was limited, colorectal cancer and endometrial cancer also exhibited relatively high NY-ESO-1 expression rates.

SAGE was evaluable in 574 samples. The SAGE expression rate was high in prostate cancer (35.3\%), oesophageal cancer $(32.9 \%)$, ovarian cancer $(26.3 \%)$ and endometrial cancer (23.1\%) (Table 4).

The tumour types for which 4 or fewer samples were evaluated, which are not listed in the tables, were as follows: thyroid, small intestine, biliary tract, pancreatic, mesothelial, breast, urothelial, sarcoma, skin, multiple myeloma and unknown primary.

\section{Co-expression of $\mathrm{CT}$ antigens}

MAGE-A4, NY-ESO-1 and SAGE mRNA expression levels demonstrated positive relationships (Fig. 1). To exclude the influence of oesophageal cancer, which accounted for

Table 1 Rates of $C T$ antigen mRNA expression

\begin{tabular}{llllll}
\hline & Positive & Negative & Not Evaluable & Total Evaluated & Positive Rate (range) \\
\hline MAGE-A4 & 199 & 376 & 10 & 585 & $34.6 \%(30.7-38.7)$ \\
NY-ESO-1 & 92 & 347 & 8 & 447 & $21.0 \%(17.2-25.1)$ \\
SAGE & 125 & 449 & 7 & 581 & $21.8 \%(18.5-25.4)$ \\
\hline
\end{tabular}

Positive rate $=100 \times($ Positive $) /($ Positive + Negative $)$. 
Table 2 MAGE-A4 expression in each tumour type

\begin{tabular}{|c|c|c|c|c|c|}
\hline Type & Positive & Negative & Not Evaluable & Total Evaluated & Positive Rate (\%) \\
\hline Head and Neck & 27 & 45 & 1 & 73 & 37.5 \\
\hline Oesophageal & 124 & 102 & 6 & 232 & 54.9 \\
\hline Gastric & 7 & 13 & 0 & 20 & 35.0 \\
\hline Colorectal & 4 & 19 & 0 & 23 & 17.4 \\
\hline Lung & 12 & 55 & 0 & 67 & 17.9 \\
\hline Ovarian & 13 & 25 & 0 & 38 & 34.2 \\
\hline Endometrial & 5 & 21 & 0 & 26 & 19.2 \\
\hline Cervical & 2 & 18 & 1 & 21 & 10.0 \\
\hline Renal & 0 & 45 & 0 & 45 & 0.0 \\
\hline Prostate & 1 & 16 & 0 & 17 & 5.9 \\
\hline
\end{tabular}

Positive rate $=100 \times($ Positive $) /($ Positive + Negative $)$.

approximately half of the assessed samples, we divided the samples into oesophageal cancer and other cancers for analysis. In the non-oesophageal tumour types, significant correlations in CT antigen co-expression, except for NYESO-1 and SAGE co-expression, were identified (Additional Fig. 1). All 3 CT antigens were assessed in 436 samples, and three tumour types with high CT antigen expression rates are shown in Fig. 2. In oesophageal cancer, $65.9 \%$ of tumours were positive for at least one CT antigen, and $38.3 \%$ expressed 2 or $3 \mathrm{CT}$ antigens. Among these $\mathrm{CT}$ antigen-positive tumour types, the median copy numbers of MAGE-A4 and SAGE in oesophageal cancer were higher than those in the other 2 tumour types (Additional Table 1).

\section{Discussion}

In this study, CT antigen expression was assessed in 585 tumour samples by quantitative real-time polymerase chain reaction (qRT-PCR). Among these tumour samples, 20-30\% exhibited MAGE-A4, NY-ESO-1 and/or SAGE expression. The MAGE-A, NY-ESO-1 and SAGE expression rates in this study were comparable to those reported previously [11, 12, 21-27]. Among the 585 tumour samples, 214 oesophageal cancer samples were evaluable for the expression of all $3 \mathrm{CT}$ antigens. This evaluation revealed a high $\mathrm{CT}$ antigen co-expression rate in oesophageal cancer.

CT antigens are promising targets for cancer immunotherapy. For example, NY-ESO-1-specific TCRengineered $\mathrm{T}$ cell therapy has shown promising antitumour responses in clinical trials [17, 28, 29]. Our data will be useful for considering the next cancer immunotherapy target. In addition, CT antigen expression and/or anti-CT antigen antibodies may have potential as biomarkers. Indeed, some reports have examined the impact of these factors on survival [30-32]. The impact of CT antigens on survival is controversial, possibly because of differences in tumour type, tumour stage and/ or tumour burden. Non-targeted antigen-specific $\mathrm{T}$ cell responses and/or antibody production, known as antigen spreading, often occurs during cancer immunotherapy. As antigen spreading may be helpful in guiding the

Table 3 NY-ESO-1 expression in each tumour type

\begin{tabular}{|c|c|c|c|c|c|}
\hline Type & Positive & Negative & Not Evaluable & Total & Positive Rate (\%) \\
\hline Head and Neck & 10 & 55 & 1 & 66 & 15.4 \\
\hline Oesophageal & 55 & 162 & 4 & 221 & 25.3 \\
\hline Gastric & 0 & 5 & 0 & 5 & 0.0 \\
\hline Colorectal & 3 & 9 & 0 & 12 & 25.0 \\
\hline Lung & 6 & 15 & 0 & 21 & 28.6 \\
\hline Ovarian & 7 & 24 & 0 & 31 & 22.6 \\
\hline Endometrial & 3 & 5 & 0 & 8 & 37.5 \\
\hline Cervical & 0 & 3 & 1 & 4 & 0.0 \\
\hline Renal & 3 & 42 & 0 & 45 & 6.7 \\
\hline Prostate & 2 & 15 & 0 & 17 & 11.8 \\
\hline
\end{tabular}

Positive rate $=100 \times($ Positive $) /($ Positive + Negative $)$. 
Table 4 SAGE expression in each tumour type

\begin{tabular}{llllll}
\hline Type & Positive & Negative & Not Evaluable & Total Evaluated & Positive Rate (\%) \\
\hline Head and Neck & 10 & 62 & 1 & 73 & 13.9 \\
Oesophageal & 74 & 151 & 3 & 228 & 32.9 \\
Gastric & 3 & 17 & 0 & 20 & 15.0 \\
Colorectal & 0 & 23 & 0 & 23 & 0.0 \\
Lung & 11 & 56 & 0 & 67 & 16.4 \\
Ovarian & 10 & 28 & 0 & 38 & 26.3 \\
Endometrial & 6 & 20 & 0 & 26 & 23.1 \\
Cervical & 1 & 19 & 1 & 21 & 5.0 \\
Renal & 2 & 43 & 0 & 45 & 17 \\
Prostate & 6 & 11 & 0 & 4.4 & 35.3
\end{tabular}

Positive rate $=100 \times($ Positive $) /($ Positive + Negative $)$.

response to immunotherapy early in the treatment course [33, 34], further assessments of CT antigens as prognostic factors are expected.

The reason that $\mathrm{CT}$ antigen co-expression is high in oesophageal cancer has not yet been clarified. The expression of MAGE-A and NY-ESO-1 is mediated by demethylation of their promoters [35-38]. As MAGE-A, NY-ESO-1 and SAGE antigens are located in the q28 region on the $\mathrm{X}$ chromosome, demethylation of common promoters or those that are located nearby may occur. In this study, a high $\mathrm{CT}$ antigen expression rate was observed in oesophageal cancer. In general, CT antigen expression seemed to increase as the tumour progressed. However, one report suggested that CT antigen expression was high in low-grade oesophageal cancer [24]. The oesophagus may be more susceptible to demethylation than other organs.

We identified 5 reports about the co-expression of CT antigens in oesophageal cancer in international journals. Among these 5 reports, 4 assessed CT antigen expression by immunohistochemistry (IHC) [21, 22, 24, 25] and 1 assessed it by PCR [23]. IHC can be performed on formalin-fixed, paraffin-embedded samples, enabling us to study a large number of samples retrospectively. However, CT antigen expression assessment via IHC can lack confidence. The anti-NY-ESO-1 antibody D8.38 recognizes not only NY-ESO-1 but also L antigen family member 1 (LAGE-1), which is also called NY-ESO-2 [21]. In addition, 57B, an anti-MAGE antibody often used to assess MAGE expression by IHC, cannot distinguish between members of the MAGE-A subfamily [21, 39]. Forghanifard et al. [23] assessed CT antigen expression in oesophageal squamous cell carcinoma by PCR and reported a positive relationship between MAGE-A4 and NY-ESO-1 and between MAGE-A4 and LAGE-1. However, their report showed a MAGE-A4 expression rate of $90.2 \%$ in oesophageal squamous cell cancer. Although the assessment method differed (IHC vs PCR), the positive rate of MAGE-A4 expression was excessively high compared with that indicated in previous reports. The positive rates of MAGE-A4, NY-ESO-1 and SAGE expression in our study were comparable to those reported previously. In addition, the number of samples assessed for CT antigen co-expression in oesophageal cancer was larger than that in the study reported by Forghanifard et al. [23] (214 samples vs 41 samples). MAGE-A4, NY-ESO-1 and SAGE mRNA expression in normal tissue is shown in Additional Fig. 2a-c. As illustrated in Additional Fig.2b, NY-ESO-1 was positive in normal prostate. Lethe et al. previously reported lack of NY-ESO-1 mRNA expression in normal prostate [40]. The frequency of NY-ESO-1 mRNA expression in prostate cancer was $11.8 \%$ in our study. Latent prostate cancer might be involved.

This study has some limitations. First, all samples were assessed in a single institute. This strategy assured consistent methods and yielded reliable results, but the universality of our assessment was not confirmed. Second, details of histological types were not collected, because this study aimed to assess CT expression in tumour samples obtained from patients who hoped to enrol in clinical studies of CT antigen-targeting cancer immunotherapies. However, histological differences may affect the rate of $\mathrm{CT}$ antigen expression even in cancers of the same primary organ. For example, MAGE-A4 was more frequently expressed in lung squamous cell carcinoma than in lung adenocarcinoma [41], and the NY-ESO-1 expression rates in synovial sarcoma and myxoid round cell liposarcoma were higher than those in other types of soft tissue sarcoma [42]. Among patients enrolled in this study, oesophageal cancer was the most common type. In Japan, oesophageal squamous cell carcinoma accounts for approximately $90 \%$ of oesophageal cancers, and oesophageal adenocarcinoma is rare [43]. Thus, the CT antigen expression rate in oesophageal carcinoma in this study could be interpreted to reflect mainly oesophageal squamous cell carcinoma. Third, qRT-PCR analyses do 


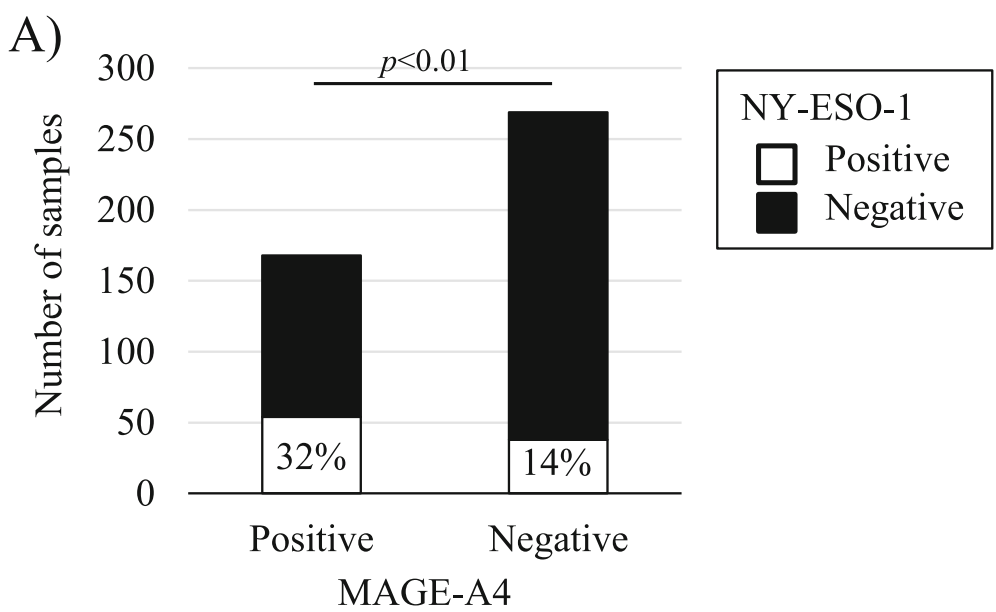

B)

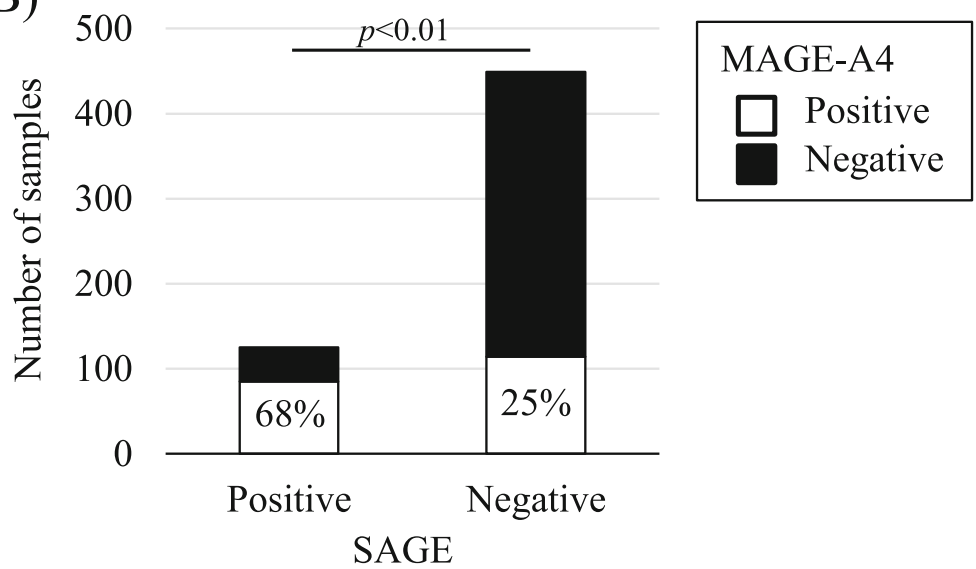

C)

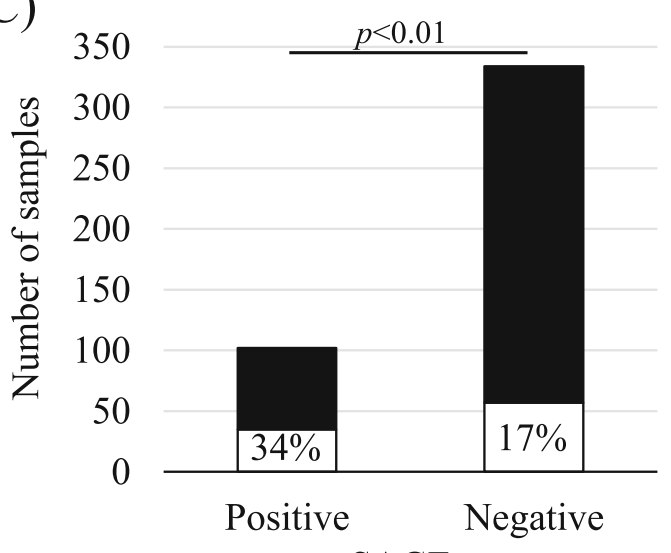

NY-ESO-1

$\square$ Positive

Negative

\section{SAGE}

Fig. 1 Relationship among MAGE-A4, NY-ESO-1 and SAGE mRNA expression. Pearson's chi-squared test of independence was used for evaluation. There was a relationship among MAGE-A4, NY-ESO-1 and SAGE expression (all $p<0.01$ )

not always reflect the CT antigen expression status in the whole tumour, because tumours often exhibit heterogeneity. Moreover, importantly, qRT-PCR analyses cannot confirm protein production in tumours, because
qRT-PCR assesses only mRNA expression. Both IHC and qRT-PCR were assessed in 41 of MAGE-A4 mRNAexamined samples and 20 of NY-ESO-1 mRNAexamined samples. In IHC analyses, MAGE-A4 positivity 

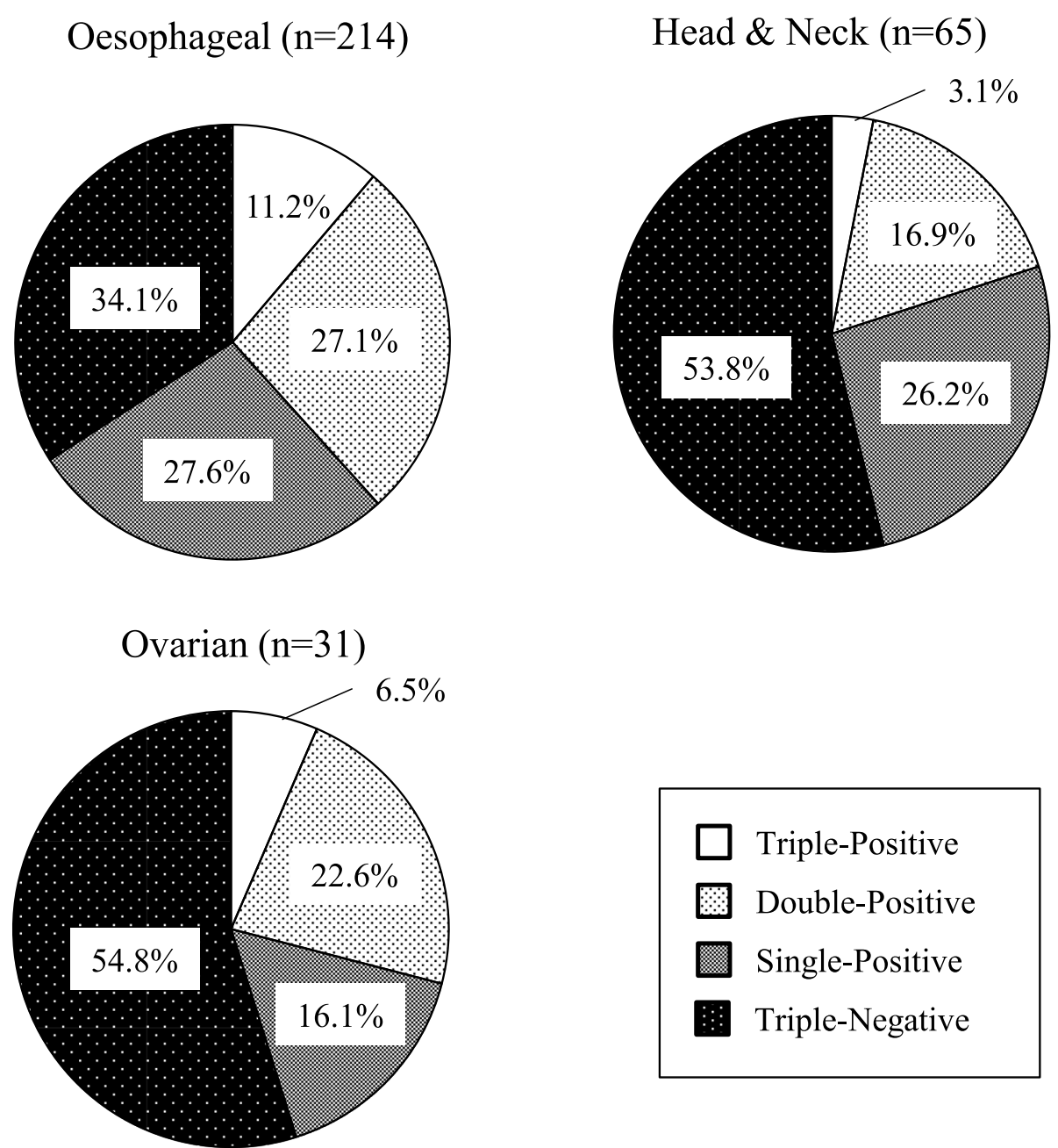

Fig. 2 Co-expression of CT antigens in tumours. All 3 antigens were assessed in 436 patients. Among 21 tumour types, 3 with a high CT antigen expression rate were selected

was defined as MCV-1 positivity and MCV-4 positivity [16], NY-ESO-1 positivity was defined as E978 positivity $[15,19]$. SAGE IHC was not assessed because of a lack of an appropriate antibody. IHC sensitivity and specificity were 64 and $75 \%$ for MAGE-A4 mRNA assessment, and 60 and 93\% for NY-ESO-1 mRNA assessment, respectively (Additional Table 2); for approximately $40 \%$ of mRNA expression-positive tumour samples, protein production could not be confirmed. Despite these limitations, the large number of tumour samples, especially oesophageal cancer samples, is a strength of this study.

\section{Conclusions}

This study assessed MAGE-A4, NY-ESO-1 and/or SAGE antigen expression in 585 tumour samples. Oesophageal cancer exhibited a high rate of CT antigen mRNA expression and a high rate of CT antigen mRNA coexpression.

\section{Supplementary information}

Supplementary information accompanies this paper at https://doi.org/10. 1186/s12885-020-07098-4.

Additional file 1 Figure 1. Relationship among MAGE-A4, NY-ESO-1 and SAGE mRNA expression in oesophageal cancer and other cancer types. Pearson's chi-squared test of independence was used for evaluation. In oesophageal cancer, there was a relationship among MAGE-A4, NY-ESO-1 and SAGE expression (A-C, left; all $p<0.01)$. In other cancer types, there was a relationship between MAGE-A4 and NY-ESO-1 expression $(p<0.01)$ (A, right) and between MAGE-A4 and SAGE expression $(p<0.01)$ (B, right) but not between NY-ESO-1 and SAGE expression ( $p=0.14$ ) (C, right).

Additional file 2 Figure 2. $C T$ antigen mRNA expression in normal tissue. mRNA expression of MAGE-A4 (A), NY-ESO-1 (B) and SAGE (C) in normal tissue was shown. First Choice ${ }^{\text {TM }}$ Human Total RNA Survey Panel ${ }^{\oplus}$, Human Breast Total RNA ${ }^{\oplus}$, Human Lymph node Total RNA ${ }^{\oplus}$, Human 
Testicle Total RNA ${ }^{\oplus}$ and Human Uterus Total RNA ${ }^{\oplus}$ (Ambion KK, Tokyo, Japan) were used.

Additional file 3 Table 1. Median levels of $C T$ antigen mRNAs in each CT antigen-positive tumour type.

Additional file 4 Table 2. MAGE-A4 and NY-ESO-1 IHC analyses of mRNA-assessed tumour samples.

\section{Abbreviations}

CAR: Chimeric antigen receptor; CT: Cancer testis; GAPDH: Glyceraldehyde-3phosphate dehydrogenase; IHC: Immunohistochemistry; LAGE-1: L antigen family member 1; MAGE: Melanoma-associated antigen; NY-ESO-1: New York oesophageal squamous cell carcinoma 1; qRT-PCR: Quantitative real-time polymerase chain reaction; SAGE: Sarcoma antigen gene; SD: Standard deviation; TCR: T cell receptor

\section{Acknowledgements}

We thank Ms. C. Sugino, Ms. K. Shirakura and J. Suzuki for technical assistance.

\section{Authors' contributions}

$\mathrm{MY}, \mathrm{SK}, \mathrm{NH}, \mathrm{HI}$ and $\mathrm{HS}$ contributed to the design of the study. MI, MY and SK performed the statistical analyses and wrote the manuscript. MI, SK, TI, SU, NS, HN and KM contributed to data and tumour sample collection. All authors contributed to data interpretation and manuscript revisions and approved the final manuscript.

\section{Funding}

This study was supported by a grant from Mie University. The funder had no role in the study design, data collection and analyses, decision to publish, or manuscript preparation.

\section{Availability of data and materials}

The datasets generated and/or analysed in the present study are not publicly available to protect patient information in the study database, but they are available from the corresponding author upon request.

\section{Ethics approval and consent to participate}

All procedures involving human participants performed in this study were conducted in accordance with the Japanese Ethical Guidelines for Medical and Health Research Involving Human Subjects and with the Declaration of Helsinki. The ethics committee of clinical research at Mie University Hospital reviewed and approved the protocol, informed consent documents and their amendments before their use (2007-2013 approval number: 817, 20142018 approval number: 2704, and UMIN number: 14008). Written informed consent for participation and for the use of tumour samples for research and publication was obtained from all patients included in this study.

\section{Consent for publication}

Not applicable.

\section{Competing interests}

S. Kageyama and H. Shiku received research funding from Takara Bio Inc. The other authors declare that they have no conflicts of interest.

\section{Author details}

'Cancer Center, Mie University Hospital, 2-174 Edobashi, Tsu, Mie 514-8507, Japan. ${ }^{2}$ Department of Immuno-Gene Therapy, Mie University Graduate School of Medicine, 2-174 Edobashi, Tsu, Mie 514-8507, Japan. ${ }^{3}$ Department of Personalized Cancer Immunotherapy, Mie University Graduate School of Medicine, 1577 Kurimamachiya-cho, Tsu, Mie 514-8507, Japan. ${ }^{4}$ Department of Gastroenterology and Hepatology, Kyoto Prefectural University of Medicine, Kawaramachi-Hirokoji, Kajii-cho, Kamigyo-ku, Kyoto 602-8566, Japan. ${ }^{5}$ Department of Gastroenterological Surgery and Oncology, Kitano Hospital, The Tazuke Kofukai Medical Research Institute, 2-4-20 Ohgimachi, Kita-ku, Osaka 530-8480, Japan. 'Department of Urology, Aichi Cancer Center Hospital, 1-1 Kanokoden, Chikusa-ku, Nagoya, Aichi 464-8681, Japan. ${ }^{7}$ Department of Gastroenterology, Matsusaka Chuo General Hospital, 102 Kobou, Kawai-machi, Matsusaka, Mie 515-8566, Japan. ${ }^{8}$ Department of Gastroenterology, Suzuka General Hospital, 1275-53, Yamanohana, Yasuzuka-cho, Suzuka, Mie 513-8630, Japan. ${ }^{9}$ United Immunity, Co., Ltd,
Room 220, Mie University Campus Incubator, 1577 Kurimamachiya-cho, Tsu, Mie 514-8507, Japan. ${ }^{10}$ Department of Oncology, Nagasaki University Graduate School of Biomedical Sciences, 1-12-4 Sakamoto, Nagasaki, Nagasaki 852-8523, Japan.

Received: 25 February 2020 Accepted: 22 June 2020

Published online: 29 June 2020

\section{References}

1. Caballero OL, Chen YT. Cancer/testis (CT) antigens: potential targets for immunotherapy. Cancer Sci. 2009;100:2014-21.

2. van der Bruggen $P$, Traversari $C$, Chomez $P$, Lurquin $C$, De Plaen E, Van den Eynde $B$, et al. A gene encoding an antigen recognized by cytolytic $T$ lymphocytes on a human melanoma. Science. 1991;254:1643-7.

3. Jager $D$, Jager $E$, Knuth $A$. Vaccination for malignant melanoma: recent developments. Oncology. 2001;60:1-7.

4. Zhang J, Wang L. The emerging world of TCR-T cell trials against cancer: a systematic review. Technol Cancer Res Treat. 2019;18:1533033819831068.

5. Leuci V, Mesiano G, Gammaitoni L, Aglietta M, Sangiolo D. Genetically redirected T lymphocytes for adoptive immunotherapy of solid tumors. Curr Gene Ther. 2014;14:52-62.

6. Brudno JN, Kochenderfer JN. Chimeric antigen receptor T-cell therapies for lymphoma. Nat Rev Clin Oncol. 2017;15:31-46.

7. De Plaen E, Arden K, Traversari C, Gaforio JJ, Szikora JP, De Smet C, et al. Structure, chromosomal localization, and expression of 12 genes of the MAGE family. Immunogenetics. 1994:40:360-9.

8. De Plaen E, De Backer O, Arnaud D, Bonjean B, Chomez P, Martelange V, et al. A new family of mouse genes homologous to the human MAGE genes. Genomics. 1999:55:176-84.

9. Chen YT, Scanlan MJ, Sahin U, Tureci O, Gure AO, Tsang S, et al. A testicular antigen aberrantly expressed in human cancers detected by autologous antibody screening. Proc Natl Acad Sci U S A. 1997;94:1914-8.

10. Chen YT, Boyer AD, Viars CS, Tsang S, Old LJ, Arden KC. Genomic cloning and localization of $C T A G$, a gene encoding an autoimmunogenic cancertestis antigen NY-ESO-1, to human chromosome Xq28. Cytogenet Cell Genet. 1997;79:237-40

11. Gnjatic S, Nishikawa H, Jungbluth AA, Gure AO, Ritter G, Jager E, et al. NYESO-1: review of an immunogenic tumor antigen. Adv Cancer Res. 2006;95: $1-30$.

12. Martelange $V$, De Smet $C$, De Plaen $E$, Lurquin $C$, Boon T. Identification on a human sarcoma of two new genes with tumor-specific expression. Cancer Res. 2000;60:3848-55.

13. Miyahara $Y$, Naota $H$, Wang L, Hiasa A, Goto M, Watanabe M, et al. Determination of cellularly processed HLA-A2402-restricted novel CTL epitopes derived from two cancer germ line genes, MAGE-A4 and SAGE. Clin Cancer Res. 2005:11:5581-9.

14. Harada N, Hoshiai K, Takahashi Y, Sakaguchi Y, Kuno T, Hishida T, et al. Preclinical safety pharmacology study of a novel protein-based cancer vaccine CHP-NY-ESO-1. Kobe J Med Sci. 2008;54:E23-34.

15. Kageyama S, Wada H, Muro K, Niwa Y, Ueda S, Miyata H, et al. Dosedependent effects of NY-ESO-1 protein vaccine complexed with cholesteryl pullulan (CHP-NY-ESO-1) on immune responses and survival benefits of esophageal cancer patients. J Transl Med. 2013;11:246.

16. Kageyama S, Ikeda H, Miyahara Y, Imai N, Ishihara M, Saito K, et al. Adoptive transfer of MAGE-A4 T-cell receptor gene-transduced lymphocytes in patients with recurrent esophageal cancer. Clin Cancer Res. 2015;21:2268-77.

17. Ishihara M, Hattori H, Arai E, Nishida Y, Takada K, Emori M, et al. Phase I/II clinical trial of NY-ESO-1-specific TCR-engineered T-cell transfer combined with a novel T-cell stimulator CHP:NE1 for patients with refractory soft tissue sarcoma. J Clin Oncol. 2019;37:TPS11074.

18. Ishihara M, Kitano S, Hattori H, Miyahara Y, Kato H, Mishima H, et al. Tumor responses and early onset cytokine release syndrome in synovial sarcoma patients treated with a novel affinity-enhanced NY-ESO-1-targeting TCRredirected T cell transfer. J Clin Oncol. 2019;37:2530.

19. Ishihara M, Tono Y, Miyahara Y, Muraoka D, Harada N, Kageyama S, et al. First-in-human phase I clinical trial of the NY-ESO-1 protein cancer vaccine with NOD2 and TLR9 stimulants in patients with NY-ESO-1-expressing refractory solid tumors. Cancer Immunol Immunother. 2020;69:663-75.

20. Soga N, Hori Y, Yamakado K, Ikeda H, Imai N, Kageyama S, et al. Limited expression of cancer-testis antigens in renal cell carcinoma patients. $\mathrm{Mol}$ Clin Oncol. 2013;1:326-30. 
21. Bolli M, Schultz-Thater E, Zajac P, Guller U, Feder C, Sanguedolce F, et al. NY-ESO-1/LAGE-1 coexpression with MAGE-A cancer/testis antigens: a tissue microarray study. Int J Cancer. 2005;115:960-6.

22. Bujas T, Marusic Z, Peric Balja M, Mijic A, Kruslin B, Tomas D. MAGE-A3/4 and NY-ESO-1 antigens expression in metastatic esophageal squamous cell carcinoma. Eur J Histochem. 2011;55:e7.

23. Forghanifard MM, Gholamin M, Farshchian M, Moaven O, Memar B, Forghani MN, et al. Cancer-testis gene expression profiling in esophageal squamous cell carcinoma: identification of specific tumor marker and potential targets for immunotherapy. Cancer Biol Ther. 2011;12:191-7.

24. Chen YT, Panarelli NC, Piotti KC, Yantiss RK. Cancer-testis antigen expression in digestive tract carcinomas: frequent expression in esophageal squamous cell carcinoma and its precursor lesions. Cancer Immunol Res. 2014;2:480-6.

25. Kerkar SP, Wang ZF, Lasota J, Park T, Patel K, Groh E, et al. MAGE-A is more highly expressed than NY-ESO-1 in a systematic immunohistochemical analysis of 3668 cases. J Immunother. 2016;39:181-7.

26. Park TS, Groh EM, Patel K, Kerkar SP, Lee CC, Rosenberg SA. Expression of MAGEA and NY-ESO-1 in primary and metastatic cancers. I Immunother. 2016;39:1-7.

27. Zhang $Y, Z$ Zhang $Y$, Zhang $L$. Expression of cancer-testis antigens in esophageal cancer and their progress in immunotherapy. J Cancer Res Clin Oncol. 2019;145:281-91.

28. Robbins PF, Morgan RA, Feldman SA, Yang JC, Sherry RM, Dudley ME, et al. Tumor regression in patients with metastatic synovial cell sarcoma and melanoma using genetically engineered lymphocytes reactive with NY-ESO1. J Clin Oncol. 2011;29:917-24.

29. Rapoport AP, Stadtmauer EA, Binder-Scholl GK, Goloubeva O, Vogl DT, Lacey SF, et al. NY-ESO-1-specific TCR-engineered T cells mediate sustained antigen-specific antitumor effects in myeloma. Nat Med. 2015;21:914-21.

30. Szender JB, Papanicolau-Sengos A, Eng KH, Miliotto AJ, Lugade AA, Gnjatic $\mathrm{S}$, et al. NY-ESO-1 expression predicts an aggressive phenotype of ovarian cancer. Gynecol Oncol. 2017;145:420-5.

31. Ueda S, Miyahara Y, Nagata Y, Sato E, Shiraishi T, Harada N, et al. NY-ESO-1 antigen expression and immune response are associated with poor prognosis in MAGE-A4-vaccinated patients with esophageal or head/neck squamous cell carcinoma. Oncotarget. 2018;9:35997-6011.

32. Kakimoto T, Matsumine A, Kageyama S, Asanuma K, Matsubara T, Nakamura T, et al. Immunohistochemical expression and clinicopathological assessment of the cancer testis antigens NY-ESO-1 and MAGE-A4 in highgrade soft-tissue sarcoma. Oncol Lett. 2019;17:3937-43.

33. Gulley JL. Therapeutic vaccines: the ultimate personalized therapy? Hum Vaccin Immunother. 2013;9:219-21.

34. Gulley JL, Madan RA, Pachynski R, Mulders P, Sheikh NA, Trager J, et al. Role of antigen spread and distinctive characteristics of immunotherapy in cancer treatment. J Natl Cancer Inst. 2017;109. https://doi.org/10.1093/jnci/djw261.

35. Wischnewski F, Friese O, Pantel K, Schwarzenbach H. Methyl-CpG binding domain proteins and their involvement in the regulation of the MAGE-A1, MAGE-A2, MAGEA3, and MAGE-A12 gene promoters. Mol Cancer Res. 2007;5:749-59.

36. Gunda V, Cogdill AP, Bernasconi MJ, Wargo JA, Parangi S. Potential role of 5-aza-2'-deoxycytidine induced MAGE-A4 expression in immunotherapy for anaplastic thyroid cancer. Surgery. 2013;154:1456-62 discussion 62.

37. Gu L, Sang M, Li J, Liu F, Wu Y, Liu S, et al. Demethylation-mediated upregulation of melanoma-associated antigen-A11 correlates with malignant progression of esophageal squamous cell carcinoma. Dig Liver Dis. 2019;51:1475-82.

38. Shi X, Chen X, Fang B, Ping Y, Qin G, Yue D, et al. Decitabine enhances tumor recognition by $T$ cells through upregulating the MAGE-A3 expression in esophageal carcinoma. Biomed Pharmacother. 2019;112:108632.

39. Juretic A, Spagnoli GC, Schultz-Thater E, Sarcevic B. Cancer/testis tumourassociated antigens: immunohistochemical detection with monoclonal antibodies. Lancet Oncol. 2003;4:104-9.

40. Lethe B, Lucas S, Michaux L, De Smet C, Godelaine D, Serrano A, et al. LAGE-1, a new gene with tumor specificity. Int J Cancer. 1998;76:903-8.

41. Shigematsu Y, Hanagiri T, Shiota H, Kuroda K, Baba T, Mizukami M, et al. Clinical significance of cancer/testis antigens expression in patients with non-small cell lung cancer. Lung Cancer. 2010;68:105-10.

42. Endo M, de Graaff MA, Ingram DR, Lim S, Lev DC, Briaire-de Bruijn IH, et al. NY-ESO1 (CTAG1B) expression in mesenchymal tumors. Mod Pathol. 2015;28:587-95.

43. Lin $Y$, Totsuka $Y$, He Y, Kikuchi S, Qiao Y, Ueda J, et al. Epidemiology of esophageal cancer in Japan and China. J Epidemiol. 2013;23:233-42.

\section{Publisher's Note}

Springer Nature remains neutral with regard to jurisdictional claims in published maps and institutional affiliations.

\section{Ready to submit your research? Choose BMC and benefit from:}

- fast, convenient online submission

- thorough peer review by experienced researchers in your field

- rapid publication on acceptance

- support for research data, including large and complex data types

- gold Open Access which fosters wider collaboration and increased citations

- maximum visibility for your research: over $100 \mathrm{M}$ website views per year

At BMC, research is always in progress.

Learn more biomedcentral.com/submissions 